\title{
Proteomic profiling of the phosphoproteins in the rat thalamus, hippocampus and frontal lobe after propofol anesthesia
}

Jing Tang ${ }^{1 \dagger}$, Qiong Xue ${ }^{1,2+}$, Hong Ding ${ }^{1}$, Zaisheng Qin ${ }^{1}$, Jinfang Xiao ${ }^{1}$, Chunshui Lin ${ }^{1}$, Youtan Liu ${ }^{3^{*}}$ and Tao Tao ${ }^{1 *}$

\begin{abstract}
Background: Propofol is a safe and effective intravenous anesthetic that is widely used for the induction and maintenance of anesthesia during surgery. However, the mechanism by which propofol exerts its anesthetic effect remains unknown. The rapid onset of phosphorylation modifications coincides with that of propofol anesthesia.

Methods: Propofol-anesthetized rat models were built and phosphorylated proteins in the thalamus, hippocampus and frontal lobe were enriched the to analyze the changes in these phosphoproteins after propofol anesthesia.

Results: Sixteen of these phosphoprotein spots were successfully identified using MALDI-TOF MS and a subsequent comparative sequence search in the Mascot database. Of these proteins, keratin 18 and the tubulin 2c chain are cytoskeletal proteins; keratin 18 and gelsolin are relevant to alcohol drowsiness. Based on Western blot analysis, we also confirmed that the phosphorylation of these proteins is directly induced by propofol, indicating that propofol anesthesia may be relevant to cytoskeletal proteins and alcohol drowsiness.
\end{abstract}

Conclusions: These identified propofol-induced phosphorylations of proteins provide meaningful contributions for further studying the anesthetic mechanism of propofol.

Keywords: 2D-gel electrophoresis, Anesthesia, Phosphorylation, Propofol, Rats

\section{Background}

Propofol is widely used in medical procedures such as gastrointestinal endoscopy in outpatient clinics [1], pediatric MRI examinations [2] and pediatric radiotherapy [3] because of its rapid onset, controllable delivery and rapid recovery. Because of its various advantages and wide range of applications, the mechanism of propofol as a general anesthetic has been the focus of increasing scientific research and much attention from anesthesiologists. Nevertheless, the specific mechanism remains unclear.

Thus far, anesthetic drugs have been known to exert their effect mainly by regulating both the synaptic transmission of key parts of the central nervous system and

\footnotetext{
*Correspondence: liuyt@hku-szh.org; taotao7819@126.com

${ }^{\dagger}$ Equal contributors

${ }^{3}$ Department of Anesthesiology, The University of Hongkong Shenzhen

Hospital, Shenzhen, China

'Department of Anesthesia, Nanfang Hospital, Southern Medical University,

Guangzhou, Guangdong, China

Full list of author information is available at the end of the article
}

ion channels in the membrane [4]. Both the neurotransmitters that play an important role in synaptic transmission and ion channels are mostly proteins. Protein modifications, especially phosphorylation and dephosphorylation, play key roles in various cellular functions, such as cell differentiation [5], cell growth and apoptosis [6]. Kondratyuk et al. [7] confirmed that depolarization can increase the phosphorylation of sodium channels in a study conducted in rat brain synaptosomes. In addition, abnormal phosphorylation can cause abnormal cellular activities. Studies suggested that abnormal phosphorylation of tau in brain tissue precedes the formation of neurofibrillary tangles in Alzheimer's disease [8]. Furthermore, increased tau phosphorylation has been reported in animals subjected to isoflurane and desflurane inhalation, which may contribute to the short-term cognitive dysfunction following anesthetic administration $[9,10]$. Therefore, detecting the changes in phosphorylation after propofol infusion will be of great help in exploring the underlying mechanism of the general anesthetic action of propofol. 
The brain is a highly interactive entity, in which a number of separate brain areas cooperate to execute biological functions [11]. The thalamus may be thought as a type of relay and is believed to act as the switchboard of information between a variety of subcortical areas and the cerebral cortex [12]. Additionally, functional brain imaging also confirmed that the thalamus is the key target for anesthetic action [13]. Studies have shown that the hippocampus is responsible for mental behaviors such as initial learning and memory as well as for conscious behavior [14]. Wei $\mathrm{H}$ et al. [15] reported that propofol affects LTD expression in hippocampal CA1 dendrites in rats, which was assumed to be the reason for propofol-induced learning and memory damage. The cerebral cortex is the final target of arousal systems, and the dorsolateral prefrontal cortex is one of most important parts of the cerebral cortex, participating in activities such as emotion recognition, voluntary movements and working memory [16] as well as the maintenance of the arousal state in mammals [17]. Thus, phosphorylated proteins in the thalamus, hippocampus and frontal lobes were extracted in an animal model induced by propofol anesthesia, and the proteins that were differentially expressed before and after anesthesia were identified using two-dimensional electrophoresis and mass spectrometry in an attempt to uncover meaningful clues about the anesthetic mechanism of propofol.

\section{Methods}

\section{Experimental animals and treatment}

Forty-eight male Sprague-Dawley (SD) rats (180-220 g) were randomly separated into two groups: the control group ( $\mathrm{C}$ group, $\mathrm{n}=24$ ) and the propofol group ( $\mathrm{P}$ group, $\mathrm{n}=24$ ). To decrease the individual difference, every 4 rats were divided into a sub-group and tissues from the same sub-group were mixed together for one gel of 2Delectrophoresis. All animal procedures were approved and conducted in accordance with the guidelines for the care and use of animals of the ethics committee of Southern Medical University. Rats in the propofol group were assigned to receive a $10 \mathrm{mg} / \mathrm{kg}$ bolus injection of propofol (Astrazeneca, UK) delivered in $1 \mathrm{~min}$ and a continuous injection of $24 \mathrm{mg} / \mathrm{kg} / \mathrm{h}$ propofol via a tail vein. The rats in the control group received an equivalent volume of $10 \%$ Intralipid (Sino-Sweden Pharmaceutical Corp., Ltd., China) via a tail vein. After $20 \mathrm{~min}$, all rats were anesthetized with urethane and sacrificed immediately by decapitation. Three brain regions were collected and frozen in liquid nitrogen. The samples were stored at $-80^{\circ} \mathrm{C}$ until further processing.

\section{Enrichment for phosphorylated proteins from tissues}

Phosphoproteins from the thalamus, hippocampus and frontal lobe of the rats were enriched on a QIAGEN
PhosphoProtein Purification column (QIAGEN, Valencia, $\mathrm{CA}$ ) according to the manufacturer's protocol. Briefly, $30 \mathrm{mg}$ of tissue from the three brain regions were homogenized in $350 \mu \mathrm{l}$ of lysis buffer containing $0.25 \%(\mathrm{w} / \mathrm{v})$ CHAPS, protease/phosphatase inhibitors, and benzonase as described in the manufacturer's protocol. The obtained phosphorylated proteins were purified with a 2D CleanUp Kit (GE Healthcare). Next, the phosphoprotein yield was determined with a 2D QUANT Kit (GE Healthcare).

\section{Two-dimensional electrophoresis (2-DE)}

An Immobiline Dry strip (pH 3-10 in the thalamus or $\mathrm{pH} \mathrm{4-7} \mathrm{in} \mathrm{the} \mathrm{hippocampus} \mathrm{and} \mathrm{frontal} \mathrm{lobe,} 24 \mathrm{~cm}$ length, GE Healthcare) was rehydrated with $400 \mu \mathrm{g}$ of phosphoprotein in $450 \mu \mathrm{l}$ of rehydration buffer containing 4\% CHAPS, $7 \mathrm{M}$ urea, $2 \mathrm{M}$ thiourea, $20 \mathrm{mM}$ Trizma base, $65 \mathrm{mM}$ DTT, 1\% IPG buffer and 0.002\% bromophenol blue for $14 \mathrm{hr}$ at room temperature. Isoelectric focusing (IEF) was performed using the Ettan IPGphor 3 IEF System (GE Healthcare) for a total of $70 \mathrm{kVh}$. For the second dimension, SDS-PAGE was performed using an Ettan DALTsix Large Vertical system (Amersham, USA) according to the following procedures: $45 \mathrm{~min}$ at a constant power of 5 watts followed by 20 watts per gel until the bromophenol blue reached the bottom of the gel. The gels were then stained with $0.12 \% \mathrm{w} / \mathrm{v}$ Coomassie Brilliant Blue G250. The 2D gels were analyzed with the DeCyder software package (GE Healthcare, USA).

\section{MALDI-TOF MS identification and database searching}

The peptide mixtures were identified on a Bruker Ultraflex III MALDI-TOF/TOF MS (Bruker Daltonics, Germany) operating in reflectron mode with $20 \mathrm{kV}$ accelerating voltage and $23 \mathrm{kV}$ reflecting voltage. Peptide mass fingerprints (PMFs) were searched against the SwissProt database using the program Mascot 2.1 (Matrix Science Ltd). The search parameters were as follows: trypsin digestion with one missed cleavage; carbamidomethyl modification of cysteine as a fixed modification; oxidation of methionine as a variable modification; peptide tolerance maximum of $\pm 0.5 \mathrm{Da}$; MS/MS tolerance maximum of $\pm 100 \mathrm{ppm}$; peptide charge of +1 ; and $\mathrm{p}<0.05$ for a local PMF search.

\section{Gene ontology analysis using GOMiner}

Differentially expressed phosphoproteins were further classified using the GoMiner software [18] in combination with the GO database, which relies on a controlled vocabulary to describe a protein in terms of its subcellular localization, molecular function, or biological process.

\section{Western blot analysis}

A total of $18 \mathrm{SD}$ rats were randomly divided into three groups: the control group ( $\mathrm{C}$ group), propofol anesthesia for 20 min group (P1 group) and propofol anesthesia 
20 min followed by an arousal state for $1 \mathrm{~h}$ group (P2 group). The rats of the $\mathrm{C}$ and $\mathrm{P}$ groups were treated in the same manner as described above. The rats of the P2 group were exposed to the propofol anesthesia used in the $\mathrm{P}$ group for $20 \mathrm{~min}$ and were sacrificed $1 \mathrm{~h}$ postanesthesia. Equal amounts of total protein $(40 \mu \mathrm{g})$ and phosphoprotein $(40 \mu \mathrm{g})$ were loaded and run on $12 \%$ SDS/polyacrylamide gels and transferred onto polyvinylidene difluoride membranes (PVDF) (Amersham Pharmacia Biotech, Piscataway, NJ). To detect keratin 18 and phospho-keratin 18, the membranes were probed with anti-cytokeratin 18 mouse monoclonal antibodies (1:500; Santa Cruz Biotechnology, Heidelberg, Germany). To detect gelsolin and phospho-gelsolin, the membranes were probed with anti-gelsolin mouse monoclonal antibodies (1:500; Santa Cruz Biotechnology, Heidelberg, Germany). To detect apolipoprotein E and phosphoapolipoprotein E, the membranes were probed with antiapolipoprotein E goat polyclonal antibodies (1:500; Santa Cruz Biotechnology, Heidelberg, Germany). The immunoreactive bands were visualized using a Kodak $2000 \mathrm{M}$ camera system (Eastman Kodak, Rochester, NY) according to the instructions of the manufacturer.

\section{Statistical analysis}

All the data were tested for a normal distribution before statistical analysis, and the statistical analysis was performed using SPSS 13.0. The statistical significance of the difference among groups was evaluated using variance (ANOVA) followed by the Student-Newman-Keuls post hoc procedure. Significance was defined as $\mathrm{P}<0.05$.

\section{Results}

Quantitative comparison and identification of phosophoprotein spots on 2D gels

To determine the change in the phosphoprotein profiles of the thalamus, hippocampus and frontal lobe in response to propofol, gel-based comparative proteomic analyses were performed. As shown in Figure 1, 21 phosophoprotein spots were found to be significantly altered among the three brain regions. Sixteen of these phosphoprotein spots were successfully identified using MALDI-TOF MS and the subsequent comparative sequence search in the Mascot database (Table 1). Derived from the thalamus, gelsolin and hemoglobin were substantially up-regulated, but keratin 18 was down-regulated in the propofol group. Derived from the hippocampus, glutathione peroxidase 3, betaine-homocysteine S-methyltransferase 1, SET domaincontaining protein 6 and cytochrome c oxidase subunit 5A were significantly overexpressed in the propofol group, while macrophage-capping protein, tubulin beta-2c chain and apolipoprotein $\mathrm{E}$ were expressed at a lower level than in the control group. The levels of delta-aminolevulinic acid dehydratase, $40 \mathrm{~S}$ ribosomal protein SA, thioredoxin- like protein 1, ATP synthase subunit alpha, metastasisassociated protein MTA1 and actin, which were derived from the frontal lobe, were decreased in the propofol group.

\section{Gene ontology analysis of propofol-responsive phosphoproteins}

The list of differentially expressed phosphoproteins was prepared for use in the GoMiner software in combination with the GO database. As seen in Tables 2, 3 and 4, the identified proteins were mainly distributed in the cytoplasm (12/16) and cytoskeleton (6/16), with functions in metabolism (10/16), regulation $(8 / 16)$, stimulus response $(6 / 16)$ and response to ethanol $(5 / 16)$.

\section{Western blot confirmation}

To verify the $2 \mathrm{D}$ results, keratin 18 and gelsolin from the thalamus and apolipoprotein $\mathrm{E}$ from the hippocampus were analyzed using Western blots. These proteins were selected because of interest in the components of the cytoskeleton. The corresponding differential keratin 18 expression patterns that were identified using 2D electrophoresis and the MALDI-TOF mass spectra are shown in Figure 2A-B and Figure 3A, respectively. To more rigorously study the effect of propofol on the protein phosphorylation, 18 rats were divided into three groups: the $\mathrm{C}$, P1 and P2 groups. The amounts of phosphorylated and total keratin 18 were determined using Western blots. As shown in Figure $4 \mathrm{~A}-\mathrm{B}$, the amount of total keratin 18 showed no significant difference among the three groups $(\mathrm{P}=0.823)$. However, compared with the amount in the $\mathrm{C}$ and P2 groups, the level of phospho-keratin 18 in the P1 group decreased dramatically in accordance with our $2 \mathrm{D}$ gels results $(\mathrm{P}=0.000)$. The corresponding differential gelsolin and apolipoprotein $\mathrm{E}$ expression patterns that were identified using 2D electrophoresis and the MALDI-TOF mass spectra are shown in Figure $2 \mathrm{C}-\mathrm{E}$ and Figure $3 \mathrm{~B}-\mathrm{C}$, respectively. As shown in Figure $4 \mathrm{C}-\mathrm{E}$, there were no observable changes in total gelsolin $(\mathrm{P}=0.084)$ and total apolipoprotein $\mathrm{E}(\mathrm{P}=0.139)$. The amount of phosphogelsolin in the $\mathrm{P} 1$ group significantly increased compared to the amount in the $\mathrm{C}$ and $\mathrm{P} 2$ groups (Figure $4 \mathrm{C}-\mathrm{D})$. ( $\mathrm{P}=$ 0.000 ). The amount of phospho-apolipoprotein $E$ in the P1 group significantly decreased compared to that in the $\mathrm{C}$ and $\mathrm{P} 2$ groups (Figure $4 \mathrm{E}-\mathrm{F})(\mathrm{P}=0.000)$. These results indicated that propofol can affect the extent of protein phosphorylation.

\section{Discussion}

Although the anesthetic effect of propofol has been extensively studied by anesthesiologists, the molecular mechanism via which propofol exerts its anesthetic effect remains unknown. Research has demonstrated that decreasing the infusion speed of propofol could effectively decrease the 

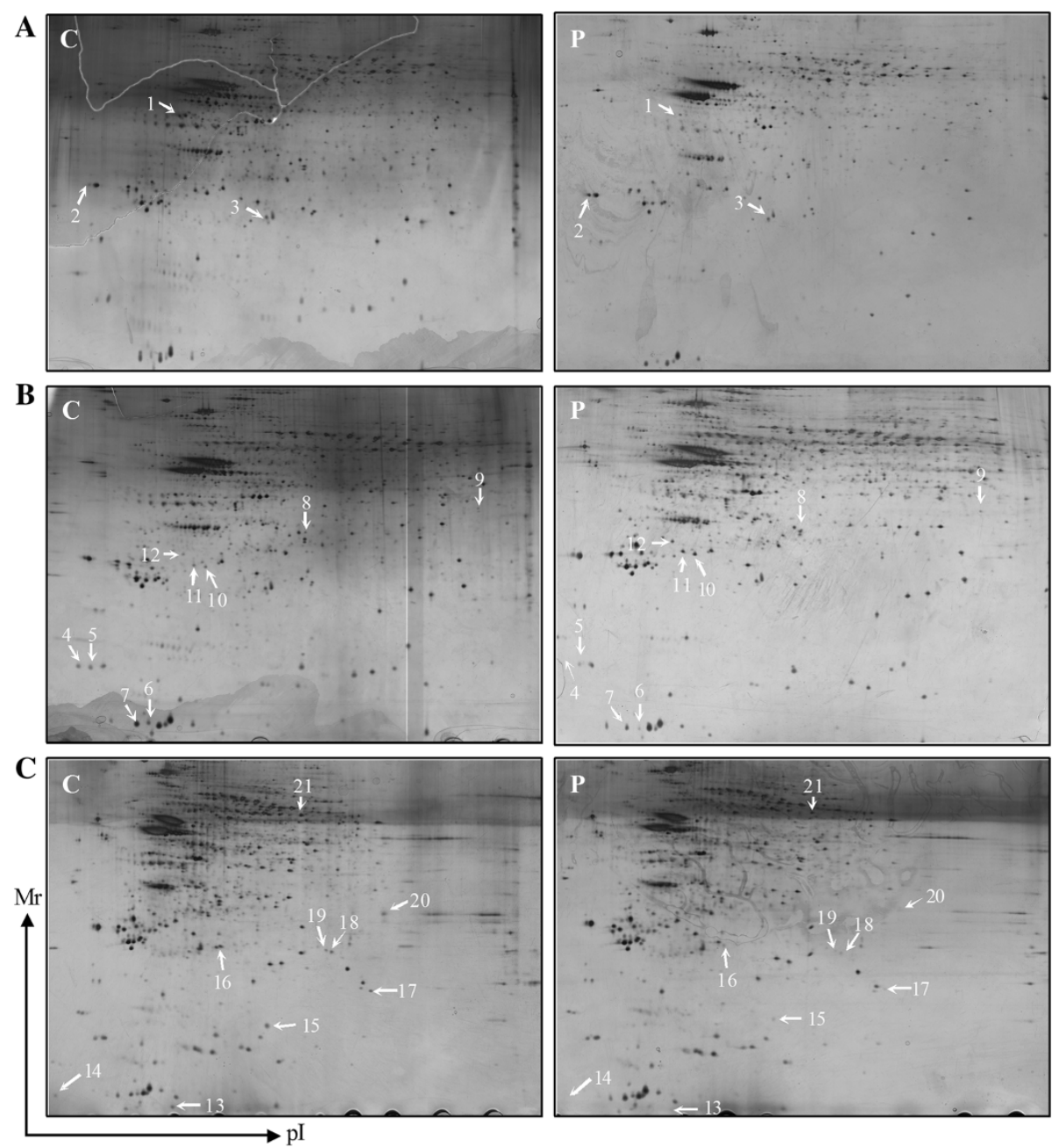

Figure 1 Representative two-dimensional gels. Control group (C), Propofol group (P). The phosphoprotein spots differentially expressed in the thalamus (A), hippocampus (B) and frontal lobe (C).

side effects resulting from propofol anesthesia [19]. Larsson et al. [20] also found that the minimum amount of hemodynamic fluctuations and the most stable anesthetic effect occurred when propofol was delivered at a speed of $10 \mathrm{mg} / \mathrm{kg} / \mathrm{min}$. Because the anesthetized rats in this experiment were not subjected to any surgical procedures, the infusion speed could be set a lower level $(24 \mathrm{mg} / \mathrm{kg} / \mathrm{h})$, with which a stable animal model was established.

Futter et al. [21] indicated that 7,14 and 10 proteins spots were found to be differentially expressed in rat brain tissues $3 \mathrm{~h}, 24 \mathrm{~h}$ and $72 \mathrm{~h}$ after propofol anesthesia, respectively. Uniform differentially expressed protein profiles were noticed in the brain tissues of rats exposed to propofol or sevoflurane, and some proteins even showed a trend with the opposite change, indicating that the mechanism of action of inhaled anesthetics was not completely identical to that of intravenous anesthesia [22]. The insoluble protein profiles in the rat hippocampus were successfully identified, and their correlation with cognitive dysfunction after anesthesia was further explored by Xuena Zhang et al. [23]. These experimental results provided a new clue for explaining the molecular mechanisms of postoperative cognitive dysfunction after anesthesia. However, these studies examined total proteins, and protein synthesis is a time-consuming process. In contrast, protein phosphorylation is a fast and reversible process that is involved in a wide variety of crucial cellular activities [6], in which the transcription and synthesis of new proteins are not involved. In all post-translational modification, phosphorylation and dephosphorylation is the most important which regulate all activites of life including cellular signal transduction, cell differentiation, cell growth and apoptosis [5-7]. In addition, the rapid onset of phosphorylation modifications coincides with the onset of the propofol anesthesia. Therefore, the profile of phosphorylated proteins in the thalamus, hippocampus and frontal lobes was 
Table 1 MALDI-TOF MS identification of differentially expressed protein

\begin{tabular}{|c|c|c|c|c|c|c|}
\hline Spot $^{a}$ & Protein name & Uniprot accession & Theoretical $\mathrm{Mr}(\mathrm{kDa})^{\mathrm{b}}$ & Total score $^{c}$ & Queries Mached $^{\mathrm{d}}$ & $\mathrm{P} / \mathrm{C}^{\mathrm{e}}$ \\
\hline 1 & Keratin 18 & Q5BJY9 & 47.76 & 72 & $100 \%$ & $\downarrow$ \\
\hline 2 & Gelsolin & Q68FP1 & 86.07 & 24 & $99.96 \%$ & $\uparrow$ \\
\hline 3 & Hemoglobin & P02091 & 15.85 & 30 & $99.95 \%$ & $\uparrow$ \\
\hline 4 & Macrophage-capping protein & Q6AYC4 & 28.80 & 148 & $100 \%$ & $\downarrow$ \\
\hline 6 & Tubulin beta-2C chain & Q6P9T8 & 49.80 & 43 & $99.96 \%$ & $\downarrow$ \\
\hline 7 & Apolipoprotein E & P02650 & 35.75 & 29 & $99.92 \%$ & $\downarrow$ \\
\hline 9 & Glutathione peroxidase 3 & P23764 & 25.27 & 87 & $100 \%$ & $\uparrow$ \\
\hline 10 & Betaine-homocysteine S-methyltransferase 1 & O96171 & 44.98 & 62 & $100 \%$ & $\uparrow$ \\
\hline 11 & SET domain-containing protein 6 & D3ZSK5 & 54.55 & 76 & $100 \%$ & $\uparrow$ \\
\hline 12 & Cytochrome c oxidase subunit 5A & P11240 & 16.20 & 29 & $99.91 \%$ & $\uparrow$ \\
\hline 13 & Delta-aminolevulinic acid dehydratase & P06214 & 36.03 & 33 & $99.95 \%$ & $\downarrow$ \\
\hline 15 & $40 S$ ribosomal protein SA & P38983 & 42.91 & 150 & $100 \%$ & $\downarrow$ \\
\hline 16 & Thioredoxin-like protein 1 & Q920J4 & 32.25 & 156 & $100 \%$ & $\downarrow$ \\
\hline 18 & ATP synthase subunit alpha & P31399 & 59.75 & 23 & $99.95 \%$ & $\downarrow$ \\
\hline 19 & Metastasis-associated protein MTA1 & Q62599 & 79.41 & 52 & $100 \%$ & $\downarrow$ \\
\hline 21 & Actin, aortic smooth muscle & P62738 & 42.01 & 62 & $100 \%$ & $\downarrow$ \\
\hline
\end{tabular}

${ }^{a}$ The numbers indicate the spot positions in 2D gel as shown in Figure 1.

${ }^{b}$ Caculated from the database entry without any processing.

'By MALDI-TOF MS analysis.

By MALDI-TOF MS analysis.

${ }^{\mathrm{e}} \mathrm{P} / \mathrm{C}$ propofol group compared with control group.

determined using proteomics in this study. Using mass spectrometry, sixteen proteins were found to be differentially expressed after propofol anesthesia, and the phosphorylation of keratin 18, gelsolin and apolipoprotein E was measured using Western blot to verify the 2D electrophoresis results.

The identified differentially expressed phosphorylated proteins were subjected to bioinformatics analysis. Six proteins, including keratin 18 , gelsolin, tubulin 2c chain, macrophage-capping protein, actin and apolipoprotein $\mathrm{E}$ were identified. These proteins form cytoskeletal structures or participate in stabilizing the cytoskeletal structure. Additionally, the changing trends in the phosphorylation

Table 2 The subcellular distribution of the identified proteins after anesthesia by propofol

\begin{tabular}{|c|c|}
\hline Subcellular & Protein name \\
\hline Cytoplasm & $\begin{array}{l}\text { Keratin 18, gelsolin, MTA1, actin, Apolipoprotein E, } \\
\text { M-capping protein, tubulin 2c chain, thioredoxin-like } \\
\text { protein 1, Betaine-homocysteine S-methyltransferase 1, } \\
40 \text { S ribosomal protein SA, ATP synthase subunit alpha, } \\
\text { Delta-aminolevulinic acid dehydratase }\end{array}$ \\
\hline Nucleus & $\begin{array}{l}\text { keratin } 18, \text { M-capping protein, SET domain-containing } \\
\text { protein } 6,40 \text { S ribosomal protein SA, MTA1 }\end{array}$ \\
\hline Cytoskeleton & $\begin{array}{l}\text { keratin 18, gelsolin, tubulin 2c chain, M-capping protein, } \\
\text { actin, Apolipoprotein E }\end{array}$ \\
\hline Mitochondrion & $\begin{array}{l}\text { Cytochrome c oxidase subunit 5A, ATP synthase } \\
\text { subunit alpha }\end{array}$ \\
\hline
\end{tabular}

levels of the three proteins were verified using Western blots, suggesting that propofol anesthesia can cause changes in cytoskeletal proteins in brain tissue.

The cytoskeleton mainly consists of microtubules, microfilaments and intermediate filaments. The tubulin 2c chain is the main structural component of microtubules, and actin is the main constituent of microfilaments. In addition to maintaining the stability of cell shape and structure, cytoskeletal proteins also regulate various molecular activities such as intracellular transport [24], energy and information transfer [25], and signal transduction.

Table 3 The molecular function of the identified proteins after anesthesia by propofol

\begin{tabular}{ll}
$\begin{array}{l}\text { Molecular } \\
\text { function }\end{array}$ & Protein name \\
\hline Binding & $\begin{array}{l}\text { MTA1, actin, Apolipoprotein E, ATP synthase subunit } \\
\text { alpha, gelsolin, Macrophage-capping protein, } \\
\text { Betaine-homocysteine S-methyltransferase 1, } \\
\text { Hemoglobin, 40S ribosomal protein SA, } \\
\text { Delta-aminolevulinic acid dehydratase }\end{array}$ \\
& $\begin{array}{l}\text { gelsolin, Glutathione peroxidase 3, tubulin 2c chain, } \\
\text { Catalytic }\end{array}$ \\
& $\begin{array}{l}\text { Apolipoprotein E, SET domain-containing protein 6 } \\
\text { Glutathione peroxidase 3, Apolipoprotein E, Delta- } \\
\text { aminolevulinic acid dehydratase, thioredoxin-like } \\
\text { protein 1 }\end{array}$ \\
Response to & gelsolin, Apolipoprotein E, Delta-aminolevulinic \\
ethanol & acid dehydratase, actin, Keratin 18 \\
\hline
\end{tabular}


Table 4 The biological processes being participated in by the identified proteins after anesthesia by propofol

\begin{tabular}{|c|c|}
\hline $\begin{array}{l}\text { Biological } \\
\text { processes }\end{array}$ & Protein name \\
\hline $\begin{array}{l}\text { Metabolic } \\
\text { process }\end{array}$ & $\begin{array}{l}\text { Keratin 18, Hemoglobin, ATP synthase subunit } \\
\text { alpha, actin, thioredoxin-like protein 1, SET } \\
\text { domain-containing protein 6, Betaine-homocysteine } \\
\text { S-methyltransferase 1, Glutathione peroxidase 3, } \\
\text { Apolipoprotein E, MTA1 }\end{array}$ \\
\hline $\begin{array}{l}\text { Biological } \\
\text { regulation }\end{array}$ & $\begin{array}{l}\text { Keratin 18, gelsolin, Apolipoprotein E, Macrophage- } \\
\text { capping protein, tubulin 2c chain, Betaine-homocysteine } \\
\text { S-methyltransferase 1, SET domain-containing protein } 6\end{array}$ \\
\hline $\begin{array}{l}\text { Developmental } \\
\text { process }\end{array}$ & $\begin{array}{l}\text { Keratin 18, ATP synthase subunit alpha, tubulin } 2 \mathrm{C} \\
\text { chain }\end{array}$ \\
\hline $\begin{array}{l}\text { Stimulus } \\
\text { reponse }\end{array}$ & $\begin{array}{l}\text { Keratin } 18 \text {, gelsolin, thioredoxin-like protein } 1 \text {, } \\
\text { Delta-aminolevulinic acid dehydratase, Apolipoprotein E, } \\
\text { SET domain-containing protein } 6\end{array}$ \\
\hline
\end{tabular}

Alterations in cytoskeletal architecture can result in changes in ion channels and account for the occurrence and development of brain-related disorders, which was first found in neurocytes. In 1981, Fukuda et al. [26] reported for the first time that cytoskeletal architecture disruption could inhibit the excitatory functions of sevrral central nervous systems (CNS) component. In 1988, Srinivasan et al., using the voltage-clamp technique [27], confirmed that the cytoskeleton was capable of modulating sodium channels in neurocytes. Propofol-induced amnesia may be related to the down-regulation of activityregulated cytoskeleton-associated protein (Arc) in the hippocampus. In contrast, the Arc mRNA level does not change significantly, indicating that propofol may exert its function by affecting protein modification [28].
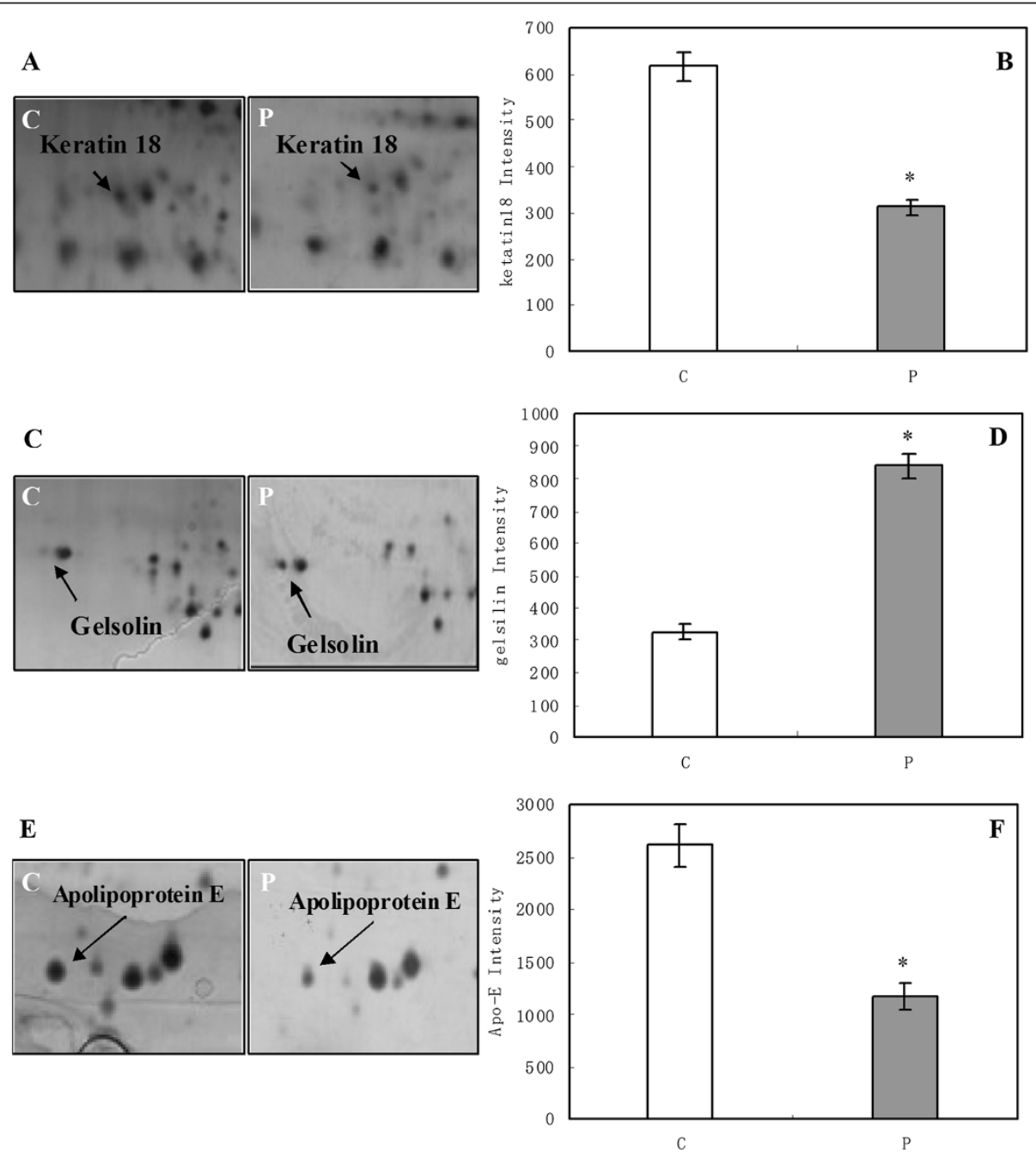

Figure 2 The change in the amounts of phospho-keratin 18, phospho-gelsolin and phospho-apolipoprotein E in the propofol group. Control group (C), Propofol group (P). The gels in the control and propofol groups have been enlarged to show the low expression of phospho-keratin 18 (A) and the high expression of phospho-gelsolin (C) and phospho-apolipoprotein $E(\mathbf{E})$ in the propofol group. The corresponding gray intensity analysis of the $2 \mathrm{D}$ results $(\mathbf{B}, \mathbf{D}, \mathbf{F})$. The densitometric analysis of each protein was calculated from 6 different gels using PDQuest software. Each bar represents the mean $\pm S D(* P<0.05$, compared with the control group). 


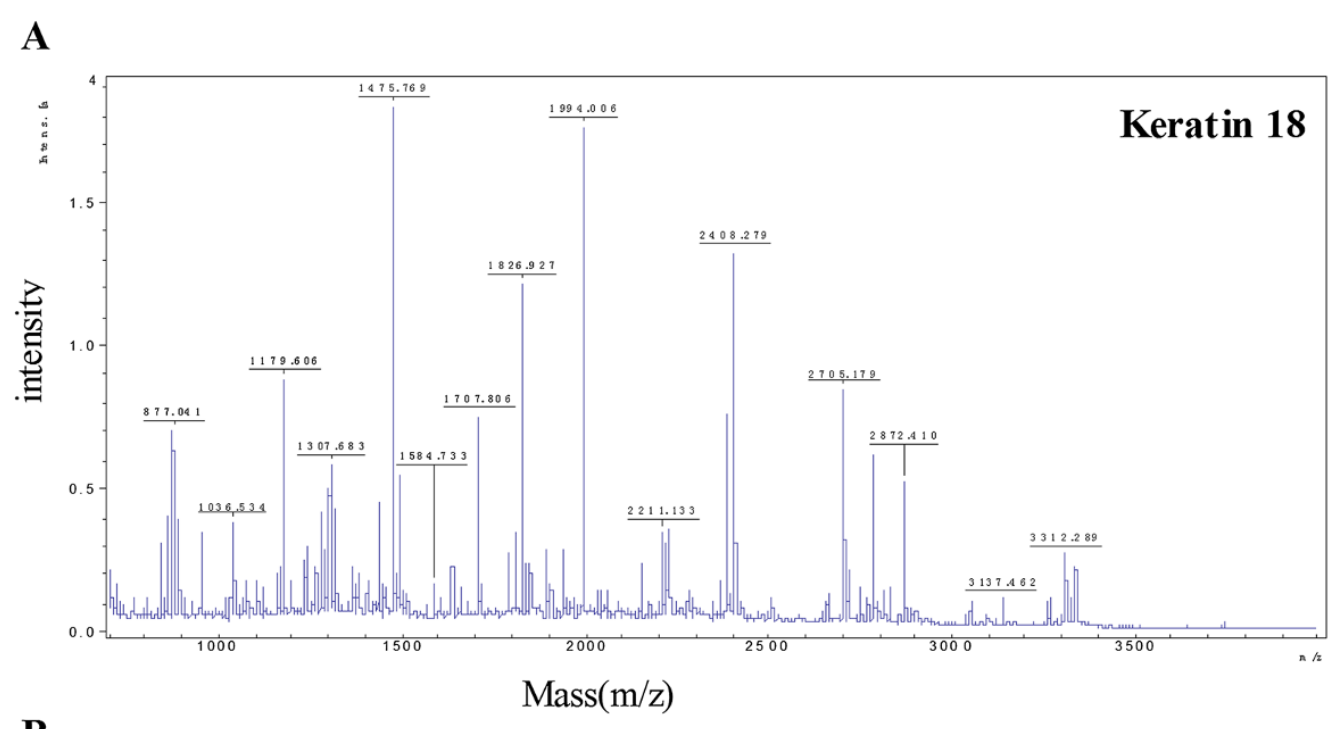

B
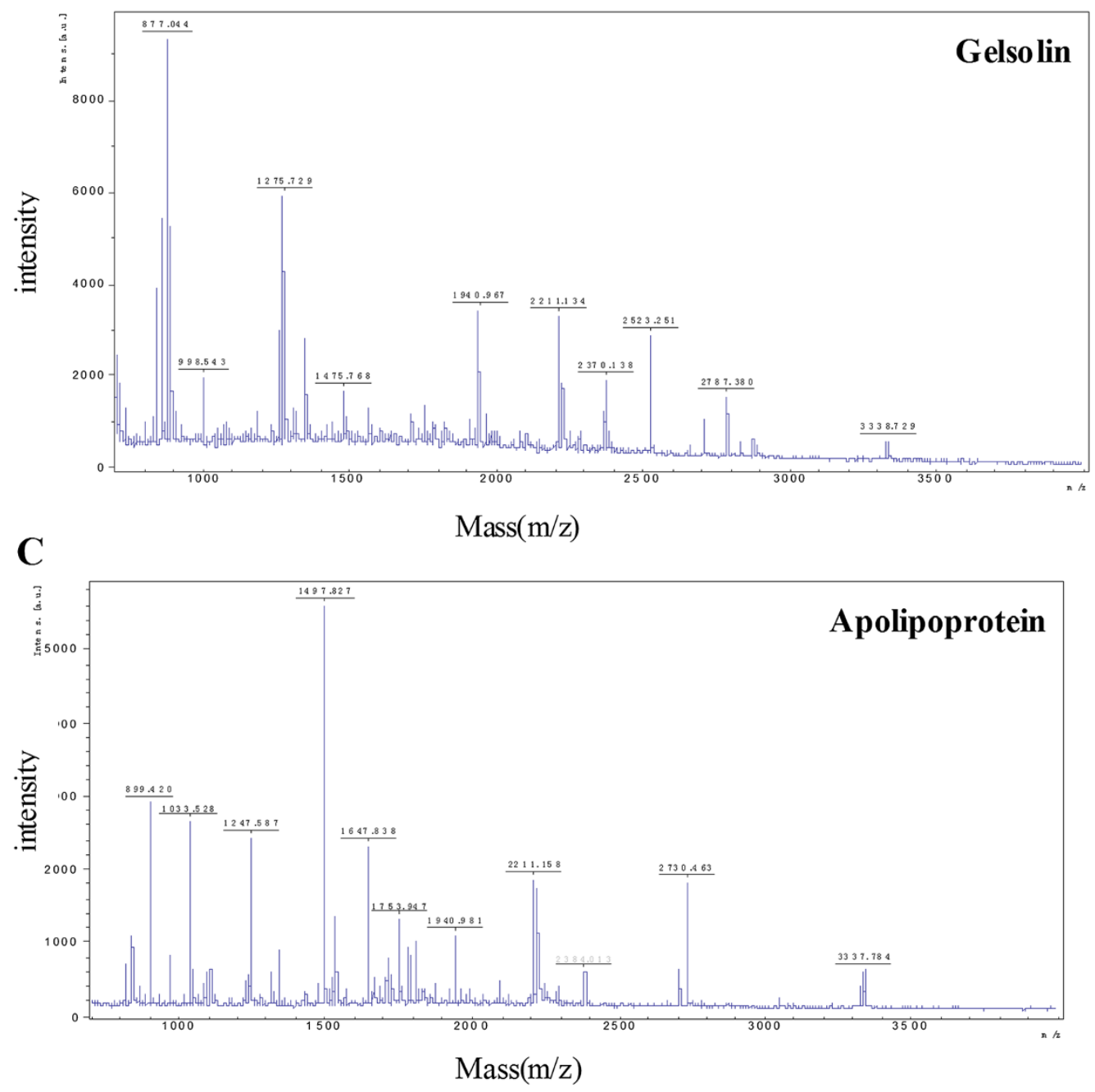

Figure 3 Identification of keratin 18, gelsolin and apolipoprotein E using MALDI-TOF MS. Mass spectrometry of in-gel trypsin digests of the proteins and analysis of the depicted peptide spectrum resulted in the identification of keratin 18 (A), gelsolin (B) and apolipoprotein E (C). 
A

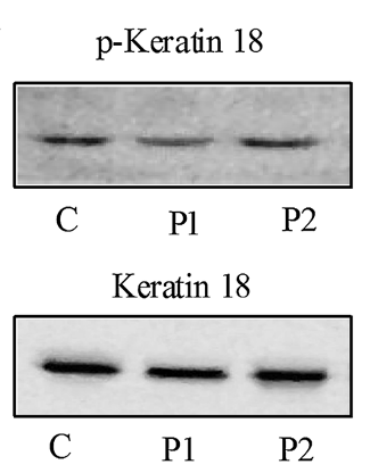

C
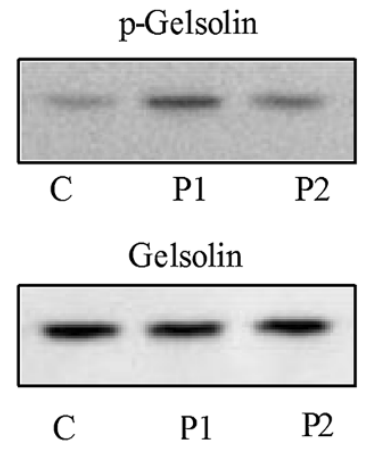

$\mathbf{E}$

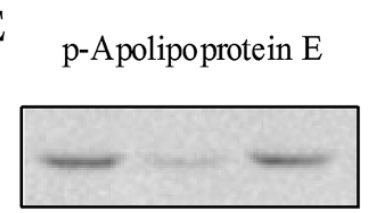

C $\quad$ P1 $\quad$ P2

Apolipoprotein E

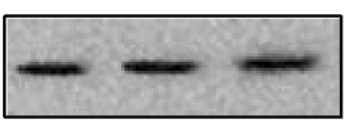

$\mathrm{C}$

P1

$\mathrm{P} 2$

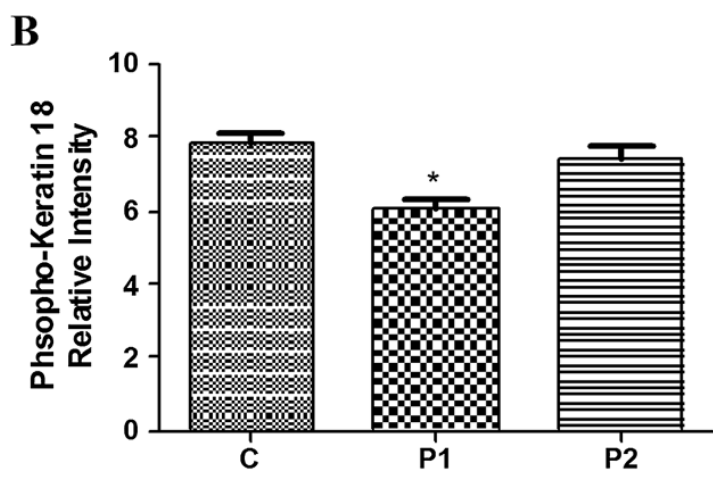

D

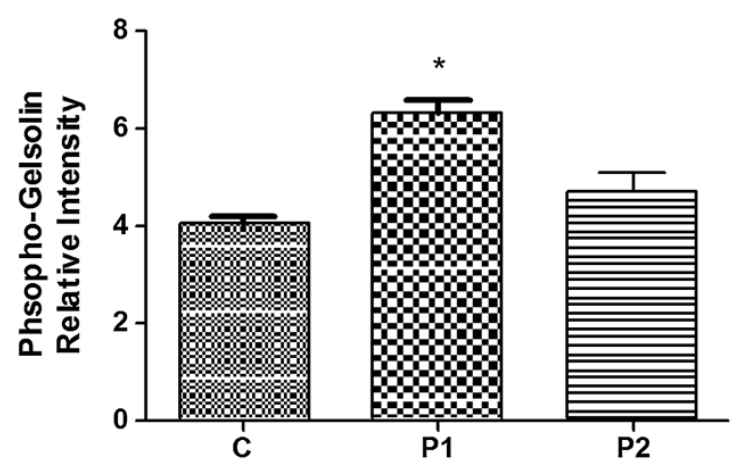

F

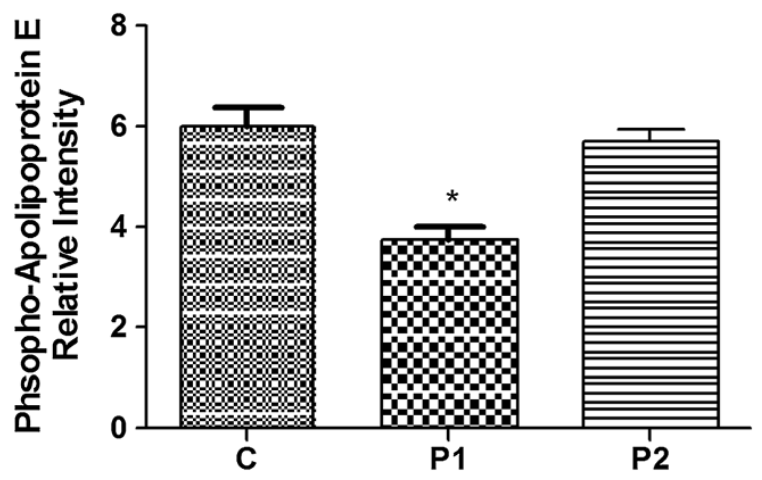

Figure 4 Confirmation of the expression of phospho-keratin 18, phospho-gelsolin and phospho-apolipoprotein E with Western blot analysis. Control group (C group), propofol anesthesia for $20 \mathrm{~min}$ group (P1 group) and propofol anesthesia 20 min followed by an arousal state for $1 \mathrm{~h}$ group (P2 group). Western blot analysis of phosphoprotein and total protein samples from the individual rats $(\mathbf{A}, \mathbf{C}, \mathbf{E})$. The corresponding gray intensity analysis of the Western blot results of the 3 groups $(\mathbf{B}, \mathbf{D}, \mathbf{F})$. Each bar represents the mean $\pm S D$ ( ${ }^{P} P<0.05, n=6$, compared with the other 2 groups).

Microtubule-associated proteins (MAPs) bind to the tubulin subunits that form microtubules. Tau proteins are type II MAPs that are abundant in neurons in the central nervous system, and their phosphorylation state can be modulated by a specific set of phosphatases and phosphokinases, which play a vital role in maintaining neuronal function and development. Hyperphosphorylation of the tau protein is assumed to be involved in the neuropathogenesis of several types of dementia, such as Alzheimer's disease and postoperative cognitive dysfunction
[8]. Sevoflurane, isoflurane and propofol can induce tau hyperphosphorylation, which may account for the occurrence of postoperative cognitive dysfunction [10,29]. Reduced apolipoprotein E phosphorylation caused by anesthetic propofol was demonstrated and was later confirmed using Western blot in this experiment. Apolipoprotein $E$ is synthesized and secreted predominantly by astrocytes and microglia in the brain, which participates in neuron repair after injury, dendritic growth and the maintenance of synaptic plasticity [30]. Apolipoprotein E also 
plays a vital role in the pathogenesis of Alzheimer's disease, where apolipoprotein $\mathrm{E}$ is found in the amyloid plaques and neurofibrillary tangles characteristic of Alzheimer's disease [31].

The deposition of monomers and polymers of hyperphosphorylated tau protein in the brain of a transgenic mice expressing apolipoprotein E4 (C112R) [32,33] suggested that apolipoprotein $\mathrm{E}$ affected tau phosphorylation. We speculate that the postoperative cognitive dysfunction induced by anesthetic propofol may result from alterations in serum apolipoprotein E levels. Nevertheless, the interwoven relationship between these factors and whether apolipoprotein E phosphorylation is involved in this process must be further explored.

Bioinformatics analysis indicated that gelsolin and keratin 18 exhibit responses to ethanol. Ethanol can weaken our body's reactions to outside stimulation, which is similar to the behavioral changes that emerge after propofol anesthesia. Amino acid neurotransmitter receptors play an important role in alcohol dependence [34]. Ethanol is both a gamma-aminobutyric acid (GABA) receptor agonist and an N-methyl-D-aspartate (NMDA) receptor antagonist, which results in degenerative alterations of the nervous system during brain development by inhibiting ERK phosphorylation $[35,36]$. The effect of ethanol is similar to that of propofol on brain stem cell apoptosis during brain development. Glutamic acid (Glu) serves as the main neurotransmitter for the inputs and outputs as well as the intrinsic circuitry of the hippocampus, which appears to be the brain region that is most sensitive to alcohol damage [37] and is the target of the anesthetic effect of propofol. In summary, the targets of and transmitters in general anesthetic agents are similar to those of the effect of alcohol on the brain. Furthermore, studies have affirmed that ethanol was able to induce the dephosphorylation of keratin 18 in the liver and kidney [38]. In our study, keratin 18 was also dephosphorylated in the rat hippocampus following propofol administration compared with the controls. We speculated that the proteins responsive to ethanol may also contribute to the anesthetic effect of propofol. However, the specific mechanisms require further study.

\section{Conclusions}

In conclusion, 16 differentially expressed phosphorylated proteins in the thalamus, hippocampus and frontal lobes were found using proteomics methods in this study. Additionally, bioinformatics were also used to analyze the common characteristics of the differentially expressed proteins to study the underlying mechanisms of the general anesthetic action. These experimental data will definitely provide meaningful references for the clarification of the mechanism of action of the general anesthetic propofol.

\section{Abbreviations}

SD: Sprague-Dawley; IEF: Isoelectric focusing; PMFs: Peptide mass fingerprints; PVDF: Polyvinylidene difluoride membranes; CNS: Central nervous systems; Arc: Activity-regulated cytoskeleton-associated protein; MAPs: Microtubule-associated proteins; GABA: Gamma-aminobutyric acid; NMDA: N-methyl-D-aspartate; Glu: Glutamic acid.

\section{Competing interests}

All authors declare that they have no competing interests.

\section{Authors' contributions}

JT, conducting of the study and editing language of the manuscript, approved the final manuscript and attested to the integrity of the original data and the analysis reported in this manuscript. QX, conducting of the study and preparing the manuscript, is the archival author and approved the final manuscript. HD, data collection, attested to the integrity of the original data and the analysis reported in this manuscript. ZQ, data analysis, approved the final manuscript. JX, data analysis, approved the final manuscript. CL, data analysis, approved the final manuscript. YL, study design, approved the final manuscript and attested to the integrity of the original data and the analysis reported in this manuscript. $T$, study design, approved the final manuscript and attested to the integrity of the original data and the analysis reported in this manuscript. All authors read and approved the final manuscript.

\section{Acknowledgements}

We thank Dr. Mingzhe Zhao and Hui Li for the help of MALDI-TOF MS identification and database searching.

\section{Funding}

This work was supported by the National Natural Science Foundation of China (81301664) and the Natural Science Foundation of Guangdong Province (S2012010008120, and S2013010014312) and Medical Scientific Research Foundation of Guangdong Province (B2011202) and the Major Program of Shenzhen Technology and Innovation Committee (201201018).

\section{Author details}

'Department of Anesthesia, Nanfang Hospital, Southern Medical University, Guangzhou, Guangdong, China. ${ }^{2}$ Department of Anesthesia, The First Affiliated Hospital of Zhengzhou University, Zhengzhou, Henan, China. ${ }^{3}$ Department of Anesthesiology, The University of Hongkong Shenzhen Hospital, Shenzhen, China.

Received: 14 October 2013 Accepted: 3 January 2014

Published: 10 January 2014

\section{References}

1. Luginbühl $M$, Vuilleumier $P$, Schumacher $P$, Stüber F: Anesthesia or sedation for gastroenterologic endoscopies. Curr Opin Anaesthesiol 2009, 22:524-531.

2. Schulte-Uentrop L, Goepfert MS: Anaesthesia or sedation for MRI in children. Curr Opin Anaesthesiol 2010, 23:513-517.

3. Mcfadyen JG, Pelly N, Orr RJ: Sedation and anesthesia for the pediatric patient undergoing radiation therapy. Curr Opin Anaesthesiol 2011, 24:433-438.

4. Alkire MT, Hudetz AG, Tononi G: Consciousness and anesthesia. Science 2008, 322:876-880

5. Seo J, Lee KJ: Post-translational modifications and their biological functions: proteomic analysis and systematic approaches. J Biochem Mol Biol 2004, 37:35-44.

6. Mumby M, Brekken D: Phosphoproteomics: new insights into cellular signaling. Genome Biol 2005, 6:230

7. Kondratyuk T, Rossie S: Depolarization of rat brain synaptosomes increases phosphorylation of voltage-sensitive sodium channels. J Biol Chem 1997, 272:16978-16983.

8. Xie Z, Tanzi RE: Alzheimer's disease and post-operative cognitive dysfunction. Exp Gerontol 2006, 41:346-359.

9. Le Freche H, Brouillette J, Fernandez-Gomez FJ, Patin P, Caillierez R, Zommer N, Sergeant N, Buée-Scherrer V, Lebuffe G, Blum D, Buée L: Tau phosphorylation and sevoflurane anesthesia: an association to postoperative cognitive impairment. Anesthesiology 2012, 116:779-787. 
10. Tan W, Cao X, Wang J, Lv H, Wu B, Ma H: Tau hyperphosphorylation is associated with memory impairment after exposure to $1.5 \%$ isoflurane without temperature maintenance in rats. Eur J Anaesthesiol 2010, 27:835-841.

11. Izquierdo I, Bevilaqua LR, Rossato JI, Bonini JS, Medina JH, Cammarota M: Different molecular cascades in different sites of the brain control memory consolidation. Trends Neurosci 2006, 29:496-505.

12. Huguenard JR, Mccormick DA: Thalamic synchrony and dynamic regulation of global forebrain oscillations. Trends Neurosci 2007, 30:350-356.

13. Alkire MT, Haier RJ, Fallon JH: Toward a unified theory of narcosis: brain imaging evidence for a thalamocortical switch as the neurophysiologic basis of anesthetic-induced unconsciousness. Conscious Cogn 2000, 9:370-386.

14. Hernández-Rabaza V, Llorens-Martín M, Velázquez-Sánchez C, Ferragud A, Arcusa A, Gumus HG, Gómez-Pinedo U, Pérez-Villalba A, Roselló J, Trejo JL, Barcia JA, Canales JJ: Inhibition of adult hippocampal neurogenesis disrupts contextual learning but spares spatial working memory, long-term conditional rule retention and spatial reversal. Neuroscience 2009, 159:59-68.

15. Howland JG, Wang YT: Synaptic plasticity in learning and memory: stress effects in the hippocampus. Prog Brain Res 2008, 169:145-158.

16. Yamasaki H, Labar KS, Mccarthy G: Dissociable prefrontal brain systems for attention and emotion. Proc Natl Acad Sci U S A 2009, 99:11447-11451.

17. Lambe EK, Aghajanian GK: Hypocretin (orexin) induces calcium transients in single spines postsynaptic to identified thalamocortical boutons in prefrontal slice. Neuron 2003, 40:139-150.

18. Zeeberg BR, Feng W, Wang G, Wang MD, Fojo AT, Sunshine M, Narasimhan S, Kane DW, Reinhold WC, Lababidi S, Bussey KJ, Riss J, Barrett JC, Weinstein JN: GoMiner: a resource for biological interpretation of genomic and proteomic data. Genome Biol 2003, 4:R28.

19. Jang HS, Choi HS, Lee MG: Effects of propofol administration rates on cardiopulmonary function and anaesthetic depth during anaesthetic induction in rats. Vet Anaesth Analg 2009, 36:239-245.

20. Larsson JE, Wahlstrom G: Optimum rate of administration of propofol for induction of anaesthesia in rats. Br J Anaesth 1994, 73:692-694.

21. Fütterer CD, Maurer MH, Schmitt A, Feldmann RE Jr, Kuschinsky W, Waschke KF: Alterations in rat brain proteins after desflurane anesthesia. Anesthesiology 2004, 100:302-308.

22. Tsuboko Y, Sakamoto A: Propofol anaesthesia alters the cerebral proteome differently from sevoflurane anaesthesia. Biomed Res 2001, 32:55-65.

23. Zhang $X$, Liu $Y$, Feng $C$, Yang $S$, Wang $Y$, Wu AS, Yue $Y$ : Proteomic profiling of the insoluble fractions in the rat hippocampus post-propofol anesthesia. Neurosci Lett 2009, 465:165-170.

24. Kapitein LC, Hoogenraad CC: Which way to go? Cytoskeletal organization and polarized transport in neurons. Mol Cell Neurosci 2011, 46:9-20.

25. Gautel M: Cytoskeletal protein kinases: titin and its relations in mechanosensing. Pflugers Arch 2011, 462:119-134.

26. Fukuda J, Kameyama M, Yamaguchi K: Breakdown of cytoskeletal filaments selectively reduces $\mathrm{Na}$ and $\mathrm{Ca}$ spikes in cultured mammal neurons. Nature 1981, 294:82-85.

27. Srinivasan $Y$, Elmer L, Davis J, Bennett V, Angelides $K$ : Ankyrin and spectrin associate with voltage-dependent sodium channels in brain. Nature 1988, 333:177-180.

28. Ren Y, Zhang FJ, Xue QS, Zhao X, Yu BW: Bilateral inhibition of gammaaminobutyric acid type $A$ receptor function within the basolateral amygdala blocked propofol-induced amnesia and activity-regulated cytoskeletal protein expression inhibition in the hippocampus. Anesthesiology 2008, 109:775-781.

29. Whittington RA, Virág L, Marcouiller F, Papon MA, El Khoury NB, Julien C, Morin F, Emala CW, Planel E: Propofol directly increases tau phosphorylation. PLOS One 2011, 6:e16648.

30. Lahiri DK: Apolipoprotein $\mathrm{E}$ as a target for developing new therapeutics for Alzheimer's disease based on studies from protein, RNA, and regulatory region of the gene. J Mol Neurosci 2004, 23:225-233.

31. Takeda M, Martínez R, Kudo T, Tanaka T, Okochi M, Tagami S, Morihara T, Hashimoto R, Cacabelos R: Apolipoprotein E and central nervous system disorders: reviews of clinical findings. Psychiatry Clin Neurosci 2010, 64:592-607.

32. Harris FM, Brecht WJ, Xu Q, Tesseur I, Kekonius L, Wyss-Coray T, Fish JD, Masliah E, Hopkins PC, Scearce-Levie K, Weisgraber KH, Mucke L, Mahley RW,
Huang Y: Carboxyl-terminal-truncated apolipoprotein E4 causes Alzheimer's disease-like neurodegeneration and behavioral deficits in transgenic mice. Proc Natl Acad Sci U S A 2003, 100:10966-10971.

33. Brecht WJ, Harris FM, Chang S, Tesseur I, Yu GQ, Xu Q, Dee Fish J, WyssCoray T, Buttini M, Mucke L, Mahley RW, Huang Y: Neuron-specific apolipoprotein e4 proteolysis is associated with increased tau phosphorylation in brains of transgenic mice. J Neurosci 2004, 24:2527-2534.

34. Faingold CL, N'Gouemo P, Riaz A: Ethanol and neurotransmitter interactions-from molecular to integrative effects. Prog Neurobio/ 1998, 55:509-535.

35. Ikonomidou C, Bosch F, Miksa M, Bittigau P, Vöckler J, Dikranian K, Tenkova TI, Stefovska V, Turski L, Olney JW: Blockade of NMDA receptors and apoptotic neurodegeneration in the developing brain. Science 1999, 283:70-74.

36. Wozniak DF, Hartman RE, Boyle MP, Vogt SK, Brooks AR, Tenkova T, Young C, Olney JW, Muglia $\amalg$ : Apoptotic neurodegeneration induced by ethanol in neonatal mice is associated with profound learning/memory deficits in juveniles followed by progressive functional recovery in adults. Neurobiol Dis 2004, 17:403-414.

37. Tsai G, Gastfriend DR, Coyle JT: The glutamatergic basis of human alcoholism. Am J Psychiatry 1995, 152:332-340.

38. Hoffert JD, Pisitkun T, Wang G, Shen RF, Knepper MA: Quantitative phosphoproteomics of vasopressin-sensitive renal cells: regulation of aquaporin-2 phosphorylation at two sites. Proc Natl Acad Sci U S A 2006, 103:7159-7164.

doi:10.1186/1471-2253-14-3

Cite this article as: Tang et al:: Proteomic profiling of the phosphoproteins in the rat thalamus, hippocampus and frontal lobe after propofol anesthesia. BMC Anesthesiology 2014 14:3.

\section{Submit your next manuscript to BioMed Central and take full advantage of:}

- Convenient online submission

- Thorough peer review

- No space constraints or color figure charges

- Immediate publication on acceptance

- Inclusion in PubMed, CAS, Scopus and Google Scholar

- Research which is freely available for redistribution

Submit your manuscript at www.biomedcentral.com/submit
C Biomed Central 